\title{
Tiempo adicional a operación de Wertheim $\left.{ }^{*}\right)$
}

\author{
Carlos Cuaresima Gutierrez \\ Miembro correspondiente de la Asociación Mex. de Gin. y Obst.
}

Managua, Nicaragua.

Con mis reconocimientos al Profesor Doctor don Genaro ZENTENO.

Después de observar en el Pabellón 14 de Ginecología del Hospital General, algunos casos de retención urinaria primero e incontinencia después, consecutivas a la operación radical de Wertheim en el tratamiento quirúrgico de neoplasias cervicouterinas en sus estados clínicos tempranos, tuve a bien recoger informes personales de reconocidos cirujanos habiendo encontrado que tales complicaciones se presentaban también a ellos. Fue entonces cuando dediqué, en la medida de mis conocimientos, la atención necesaria para estudiar su fisiopatología y la forma como pudiera evitarse tan frecuente complicación.

En tal sentido, las presentes anotaciones no tratan sobre opiniones terapéuticas de neoplasias cervico-uterinas, ni sobre el momento en que aquéllas deben emplearse, sino sobre determinado acto de la operación de Westheim, esto es, en el que tiene que ver con la vejiga urinaria y los trastornos que éste casi siempre y subsecuentemente produce en el funcionamiento vesical.

Todo ello, unido a la sugerencia de un tiempo quirúrgico a la operación en uno de sus actos y que al parecer lo completa, tengo el honor de presentar a la Honorable Asociación Mexicana de Ginecología y Obstetricia, como una comunicación preliminar ya que carezco de casuística, y con el único propósito que si es aceptado por la experiencia, haya podido contribuír en algo al alivio de molestias consecutivas a la terapéutica quirúrgica de pacientes portadoras de neoplasias cervico-uterinas.

* Reproducido de "Ginecología y Obstetricia". Vol. VIII. No 8. Enero, Febrero 1953: México. 


\section{RESUMEN ANATOMICO Y FISIOLOGICO DE LA MICCION}

La vejiga urinaria no es un órgano extraño en la formación, posición y situación de los órganos genitales femeninos, contribuyendo en algunos casos a su fisiología, como sucede en ciertos hermafroditas cuyas vaginas se abren en la uretra sirviendo esta última para dar paso a sangre del útero menstruante. Vejiga, matriz, aretra y vagina se forman a un mismo tiempo en la vida embrionaria presentando y conservando sus relaciones de vecindad y de verdadera unidad anatómica por medio del seno urogenital. Más adelante, cuando los órganos en referencia han llegado a una edad adulta, por decirlo así, las relaciones que guardan respecto a su vecindad continúan interesantes para llamar la atención. Sin exponer detalles anatómicos completos de la vejiga más que los que guardan relación con los genitales femeninos y los que imprescindiblemente se derivan de su inervación, mencionaremos los siguientes:

a) Relaciones y semejanza de estos órganos.

Vejiga urinaria y matriz son órganos huecos, situados en la línea media de la cavidad pelviana, extraperitoneales y con una salida al exterior. Son únicos, quedando la vejiga cuando está vacía por delante del útero y vagina siguiendo sensiblemente su anteflexión y anteversión anatómicas y guardando uretra y vagina un paralelo hacia el exterior. Cuando está llena tiende a elevarse en la cavidad abdominal influyendo de este modo sobre la posición normal del útero, principalmente, cuando el referido órgano de la vejiga se encuentra en hiperdistensión.

Ambos órganos tienen elementos de sostén y de suspensión comunes (Diafragma urogenital y sus fascias en el piso pelviano). El uraco y los ligamentos umbilicales son órganos de suspensión vesical quizás similares en sus funciones a los ligamentos redondos de la matriz. El Retináculum úteri es base de sostén y de fijación de ambos órganos.

b)-Inervación de la vejiga.

La vejiga urinaria está inervada por fibras del simpático y parasimpático. Las primeras vienen representadas por filamentos nerviosos que se encuentran a lo largo de la aorta abdominal y cuya red se designa con el nombre de plexo preaórtico 


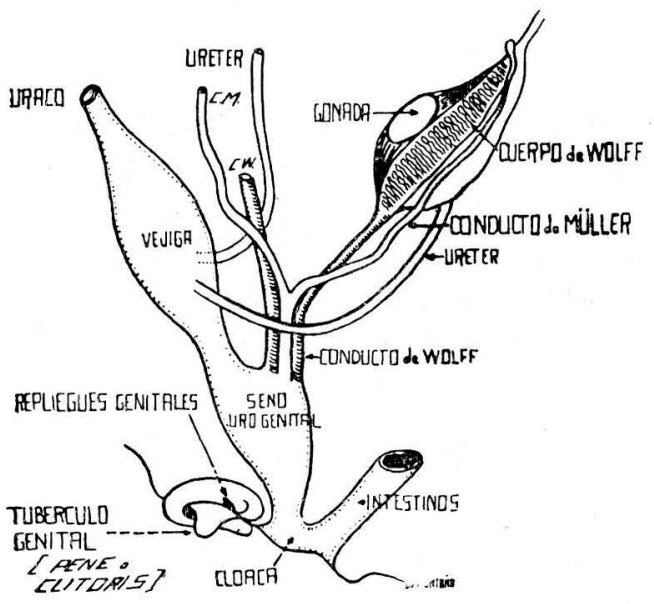

Vejiga urinaria y órganos genitales presentan una verda. dera unidad anatómica por medio del seno ourogenital en la vida embrionaria.

y que tienen su origen en el plexo celíaco y ganglios renales. A cada lado de este plexo van otras fibras nerviosas originadas de los ganglios lumbares y que se fusionan con las fibras del plexo pre-aórtico por delante de la quinta vértebra lumbar y de la bifurcación aórtica, para formar en la vértebra siguiente, es decir, en la primera sacra, el nervio pre-sacro que lo forma una raíz media y dos laterales. Este nervio se divide a su vez en dos porciones de fibras (nervios hipogástricos) que siguen las paredes laterales del recto hasta llegar a los ganglios hipogástricos en donde sufren una interrupción, para continuar de este modo, a lo largo de los vasos, hasta los tejidos de las vísceras que inervan y que son: vejiga, útero, parte de trompa de Falopio y vagina.

Las segundas fibras nerviosas o sean las del parasimpático que inervan la vejiga, vienen del II, III y IV nervios sacros, siendo el III el de mayor importancia. Estos nervios, principalmente el III, forman los nervios erigentes que atraviesan los ganglios hipogástricos sin interrumpirse, yendo a terminar en "diminutas estaciones celulares" en los órganos que inervan presentando en ellos el antagonimo siguiente:

Nervio simpático

Inhibe el peristaltismo

Contrae los esfínteres

de los órganos.

Vaso constrictor.

Inhibe las secreciones

glandulares.

\section{Nervio parasimpático}

Determina el peristaltismo.

Relaja los esfínteres.

Vaso dilatador.

Aumenta las secreciones. 
c) Fisiologia de la micción.

Se cree que las fibras medias del presacro son vasomotoras en parte y que sus raices laterales obran sobre la musculatura de la vejiga. El estímulo del simpático produce contracción de los orificios uretéricos, vasoconstricción en el trígono y contracción del esfínter interno de la vejiga. (El esfínter externo está inervado por nervios pudendos). Sin embargo, si se secciona el simpático el esfínter interno permanece cerrado. Para este hecho y experimento importante en humanos, Learmonth sugiere que el simpático únicamente refuerza el cierre del esfínter y que éste posee "un tono inherente". En las resecciones del pre-sacro a fin de evitar sufrimientos dolorosos en determinados pacientes, el dolor vesical disminuye pero no queda abolido y el control normal de la micción se restablece al poco tiempo. De todo ello se deduce que el simpático no es indispensable para el acto de la micción.

En cambio, es un hecho que la sección del parasimpático vesical vuelve incapaz al paciente para orinar voluntariamente, encontrándose paralizada la musculatura vesical. En consecuencia, el parasimpático por sí solo es necesario para el acto de la micción. Por otra parte, es conocido que existe una inervación intrínseca vesical.

La micción en la infancia y en la edad adulta se diferencia por el origen de estímulo del centro nervioso. En la primera, el acto reflejo está constituído sencillamente por las ramas aferentes vesicales que llevan el estímulo de la distensión vesical a centros reflejos medulares. En la segunda y sucesivas épocas de la vida, este reflejo será auxiliado por la intervención de los centrcs superiores del encéfalo a los que quedará sometido en lo que se refiere a la influencia de la voluntad.

La función de evacuación reviste entonces dos aspectos: el primero, condicionado por la distensión paulatina y progresiva del rendimiento urinario en este reservo-rio, cuya capacidad fisiológica corresponde al umbral de excitación en que se contrae el órgano sincrónicamente, que como víscera hueca posee la vejiga. La contracción de su esfínter interno se opone al vaciamiento del órgano y este fenómeno es inconsciente. En un segundo aspecto, la vejiga, después de adaptarse a un equilibrio sustentado principalmente por sus propiedades elásticas, queda en condiciones semejantes a la inicial, hasta que el volumen que paulatinamente aumenta, vuelve a despertar este fenómeno que sigue en el terreno 
de lo inconsciente hasta que se alcanza el umbral de excitación que trasponiendo el de los centros medulares, se eleva a los centros supeniores para ser auxiliado en caso necesario por el esfínter externo, músculos elevadores y perineales para oponerse o realizar la evacuación de dicho órgano.

\section{ACTOS DE LA OPERACON DE WERTHEIM EN RELACION CON LOS ORGANOS VECINOS}

Conocido es que la operación radical de Wertheim consta de tres actos principales previos a la resección de los tejidos invadidos; ellos son:

1. Despegamiento de vejiga urinaria.

2. Denudación de ureteres.

3. Despegamiento de recto.

No trataremos más que del despegamiento de vejiga, denudación de ureteres y de la forma en que queda la cavidad pelviana después de la extirpación de los órganos y tejidos enfermos, a fin de simplificar los hechos.

\section{a) Despegamiento de vejiga y denudación de ureteres.}

La incisión transversal del peritoneo vesical se hace a nivel del orificio interno del itsmo y que corresponde al límite de la reflexićn peritoneal en el pequeño fondo vesico-uterino; posteriormente, se prolonga esta incisión a expensas de la hoja anterior del ligamento ancho hasta la altura de los ligamentos redondos. El despegamiento vesical de cara anterior de itsmo y vagina se lleva a efecto también en dos tiempos, por razones de técnica, usando tijeras curvas de punta roma o gasa, preferible las primeras. La disección separa toda la cara postero-inferior vesical de itsmo y tercio superior vaginal, correspondiendo este último límite al nivel del cuello vesical. Los ureteres, una vez encontrados en la pared pélvica o en el cruzamiento con la uterina, son desnudados allí, en su porción parametrial y paravaginal hasta su entrada en la vejiga.

b) Cómo queda la cavidad pelviana después de la extirpación de los tejidos enfermos.

Una vez llevada a efecto la denudación de ureteres, despegamiento de vejiga y recto de cara anterior y posterior de vagina 


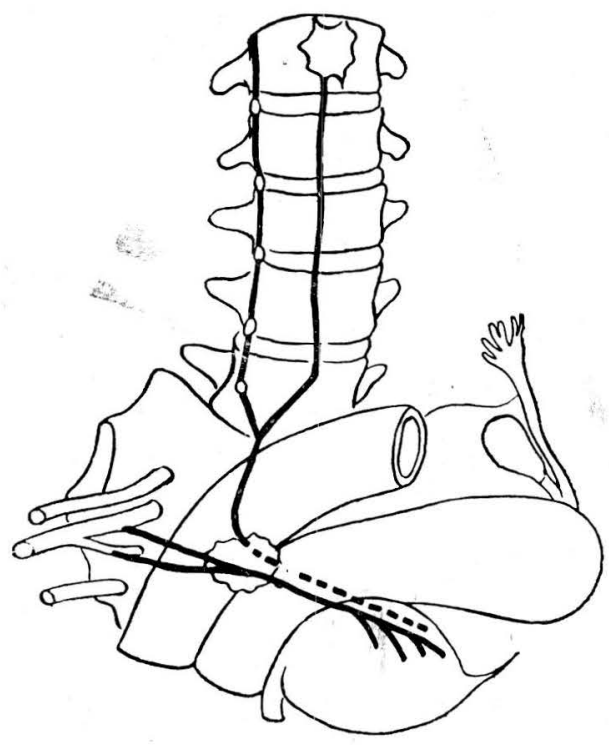

El simpático sufre interrupción en el ganglio hipogástrico; el parasimpático lo atraviesa directamente sin inte. rrumpirse. Ambos inervan la vejiga.

respectivamente de los otros tiempos de liberación de matriz, se procede a extirpar esta última con anexos, parametrios y tercio superior de vagina, así como ganglios linfáticos para-uterinos y los demás de la cadena ganglionar cuando esto último resulta factible. Al quedar en este estado la cavidad pelviana, lo que más llama la atención es la vejiga urinaria al descubierto y presentando una extensa superficie cruenta en toda su cara posteroinferior hasta el nivel del cuello vesical. La posición que este órgano toma entonces es la de cualquier cuerpo que ha perdido su soporte. Semeja un fondo de saco colgante suspendido en su vértice por el cordón medio y los laterales y por los tejidos deslizables que la unen al pubis. Es de hacer notar que ha perdido su nido y apoyo que le ofrecen normalmente la cara anterior del itsmo, cuello uterino, tabique compacto vesico-vaginal y sobre todo, por haberse destruído la unidad de organización anatómica del Retináculum úteri que forma en la pelvis una sola estructura crucial de sostén de matriz y vejiga

Por otra parte, la extensión de la lesión de despegamiento que recibe la vejiga presenta un acortamiento aparente si ésta se encuentra vacía; pero si antes de peritonizar se dispusiera llenarla de líquido, aumentaría su amplitud, dando a conocer la verdadera extensión de despegamiento, lo que hace pensar en la gran zona denervada, cruenta, sin apoyo posterior y libre, que se 


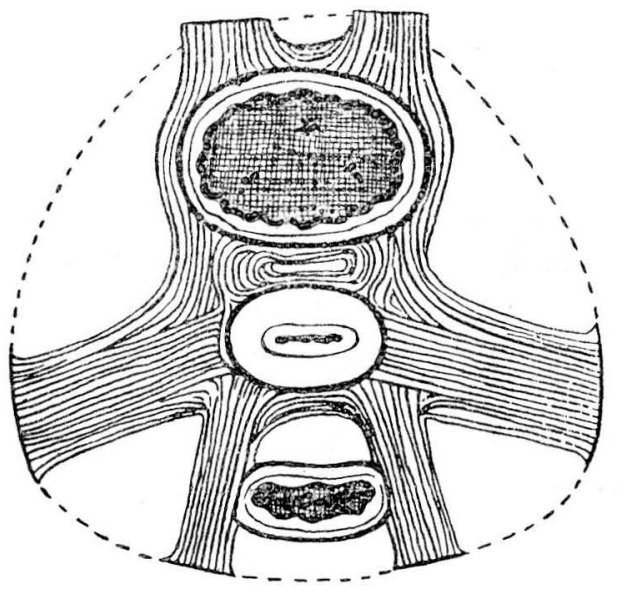

El Retináculum uterino forma en la pelvis una sola estructura crucial de sostén de matriz y vejiga.

abandona en el fondo de la cavidad pélvica bajo el velo peritoneal vesico-rectal reconstruído.

En consecuencia, la vejiga urinaria se encuentra prolapsada, facilitando por sólo los hechos de debilitamiento, pérdida de apoyo y desplazamiento de su pared postero-inferior, ulteriores trastornos urinarios de origen físico-mecánico.

Presenta, asimismo, la cavidad pelviana: el recto con su cara anterior lacerada, vagina boquiabierta, muñones de utero-sacros, de vasos uterinos, de ligamentos cardinales, ligamentos redondos; grandes vasos pélvicos al descubierto y ureteres denudados en una gran parte de su extensión, libres y pendientes estos últimos, sin ninguna trama de tejido de protección.

Es en esta forma o situación cuando se procede a cerrar o no vagina, no dejar gasa o dejar, y unir peritoneo vesical con peritoneo pélvico, para peritonizar el fondo de la cavidad pelviana.

\section{FRECUENTE COMPLICACION POST-OPERATORIA: RETENCION DE ORINA E INCONTINENCIA DESPUES}

Una sonda uretral o de Pezzer es dejada en cavidad vesical después de la operación durante seis a ocho días para mantener la vejiga urinaria en reposo y establecer los cuidados post-operatorios del caso. Casi siempre, en los primeros días de la segunda semana y una vez quitada la sonda, la paciente inicia sus trastornos urinarias con incapacidad funcional para efectuar una micción voluntaria y la retención urinaria se establece poco a 
poco hasta llegar a una franca incontinencia. Esta incontinencia de orina se establece directamente por rebosamiento y no es sino en los estados reversibles de estos padecimientos que va quedando una incontinencia de esfuerzo, ortostática, para recobrar después la paciente sus micciones normales.

Los exámenes cistoscópicos que durante estos trastornos se han hecho, casi siempre han arrojado lo siguiente: aumento de trama vascular en mucosa vesical particularmente en trígono y fondo. Vasos dilatados en esos sitios; depósitos de pequeñas concreciones calcáreas e hipotonía vesical. En otras ocasiones los ureteres participan de las lesiones descritas, de tipo entreabierto, por probable hipotonía ureteral.

\section{FISIOPATOLOGIA Y MECANISMO DE ESTOS TRASTORNOS}

Comúnmente se explica que los trastornos urinarios son debidos a la denervación vesical sufrida al despegar vejiga de itsmo y pared anterior de vagina; sin embargo, si tomamos en cuenta que las fibras nerviosas de la vejiga llegan a ésta por su cara. posterior y laterales y que el despegamiento o disección se efectúa por cara postero-inferior y alguna parte de caras laterales por resección de parametrios anteriores, se deduce, que no todas las fibras nerviosas se seccionan y que muchas de ellas escapan al seccionamiento. Se recordará también que de las fibras nerviosas del simpático y parasimpático seccionados, únicamente la sección de estas últimas incapacitan la micción normal por parálisis de la pared vesical, como hemos visto anteriormente. Es por ello, que la "denervación vesical" en sí, es un término muy global y debe atribuírsele la causa a la sección parasimpática esencialmente, dentro de las consideraciones apuntadas. Existe, además, una inervación intrínseca vesical y "un tono inherente" de su esfínter interno. Todo esto explica el por qué la mayoría de los trastornos vesico-urinarios consecutivos a la operación de Wertheim sean reversibles, bajo el punto de vista neurogénico.

Por tal motivo, me permito llamar la atención sobre otras causas igualmente importantes y que se derivan de hechos clínico-físico-mecánicos propiamente dichos, de infecciones secundarias o coexistentes a neoplasias cervico uterinas y de intervenciones quirúrgicas en estadios clínicos avanzados. 


\section{a) Causas físico-mecánicas propiamente dichas.}

El punto de apoyo o de soporte que anatómicamente tiene la vejiga y del que ya nos hemos ocupado, lo pierde por la operación; al perderlo, baja o cae al fondo y pared postero-inferior vesical. Eisto origina la formación de un bajo fondo muy acentuado cue condiciona retención parcial de orina. Si la retenciśn de orina persiste, la vejiga se distiende hasta llegar a una superdisterısión; el volumen del líquido y la presión intravesical, vencen la resistencia del esfínter para dar paso a un poco de orina con lo que disminuye la presión y distensión; más tarde. cuando estos fenómenos físicos se repiten vuelve a salir orira y asi sucesivamente. En otras palabras y ampliando más los conceptos puntuaiszarenos lo siguiente:

1. Existe una falta de apreciación quirúrgica al considerar de muy poca extensión la superficie cruenta de despegamiento vesicai, quizás, por trabajar en vejiga vacía, siendo la extensión proporcionada que necesitamos conocer la que se presenta cuando lá vejiga está llena, porque en esta forma es como cumple sù misión tisiológica desde el sexto al octavo días post-operatorios en que se ha quitado la sonda. Esta superficie cruenta aurienta considerablemente cuando la vejiga se llena.

2. Al aumentar dicha extensión, disminuye el tono muscular, aumenta la presión intravesical y el peso que por sí solo ejerce el líquido sobre el trígono y bajo fondo vesical, favorecidos por el arrastre que la vejiga sufre al peritonizarla comúnmente y por la posición en decúbito dorsal de la paciente, hacen bajar aún más: la pared vesical postero-inferior hasta formar un fondo de saco porlapsado.

3. En una fase ulterior, la pared posterior uretral paricipa de la caída de la pared vesical citada por relajamiento de sus tejidos. El cuello vesical desciende y el diámetro uretral se agránda con acortamiento aparente de dicha uretra, presentando ésta un meato entreabierto, para dar paso a la incontinencia de orina.

Fácil es comprender que este proceso patológico vesical que ze instala no es debido únicamente a la denervación, ya que a la vejiga le queda la inervación que le llega por parte de sus ca-ras laterales, su inervación intrínseca y el "tono inherente" de su esfinter interno, sino también, a la falta de fuerza contráctil suficiente de su pared postero-inferior que se deja distender por no tener el apoyo o soporte que anatómicamente tiene la vejiga 
y que le ofrecen: istmo y cuello uterino, parametrios, ligamentos pubo-vesico-uterinos y tercio superior de tabique compacto vesico-vaginal; todo ello extirpado extensamente durante la operación radical de Wertheim.

b) Infecciones secundarias o coexistentes de cervix, parametrios o vejiga urinaria.

La cervicitis, parametritis y cistitis, crónicas o agudas, de origen infeccioso, secundarias o coexistentes con neoplasias cervicales, además de ser causas de errores de apreciación del estadío clínico neoplásico, si no se tiene cuidado, dificultan más tarde, durante la intervención, la denudación de ureteres en su porción parametrial y el despegamiento vesical. Estos estados inflamatorios circunvecinos y principalmente el de la vejiga misma, con el trauma operatorio, contribuyen a entorpecer los reflejos urinarios en los días que siguen a la operación. Es probable, que sólo la presencia o el temor del dolor vesical pueden inmovilizar la vejiga cooperando así a la retención de los primeros días.

\section{c) Intervención quirúrgica en estadios clínicos avanzados.}

Mientras más recientes es el diagnóstico y estadío clínico de neoplasias cervico-uterinas, más sano se encuentra el tejido vecino vesical ofreciendo mayor elasticidad y menos dificultad operatoria. Los estadíos clínicos que se alejan de la neoplasia cervical "in situ", hacen más laboriosa la operación por su infiltración avanzada, contribuyendo a traumas de vejiga y de ureteres que unidos a la infiltración propia vesical, la hacen incapaz de sostener su funcionamiento normal, colocándola en un mal pronóstico post-operatorio. Para mejor exposición de la suerte que corren no sólo vejiga y ureteres sino todo el árbol urinario, en relación con el grado de neoplasias cervicales , me permito hacer especial referencia al Capítulo que trata de la "Repercusión que el neoplasma cervical tiene sobre el árbol urinario" del Profesor Dr. G. Zenteno. (Ginecologia, 1947).

\section{d) Otras causas que contribuyen a estos trastornos.}

Resecciones amplias de la operación. Se ha observado que mientras más extensas son las resecciones del Wertheim, más frecuentes se presentan los trastornos vesicales. 
Edad de la paciente. Trígono y bajo fondo vesical son mayores y presentan paredes flácidas en la edad avanzada.

El anestésico es también causa de la retención urinaria de los primeros días, por la depresión del sensorio.

Ciertas drogas como las estupefacientes, disminuyen también la sensación de orinar retardando el concepto o el grado de distensión vesical que las fibras parasimpáticas llevan a los centros nerviosos.

\section{PLAN TERAPEUTICO QUE SE PROPONE}

Considerando las causas fisiopatológicas enumeradas, la conducta clínico-médica-quirúrgica a seguir, será preventiva en toda su línea, permitiéndome presentar la siguiente norma:

\section{A. Cuidados pre-operatorios.}

1. Elección de casos en estadíos clínicos puramente quirúrgicos y libres de estados infecciosos coexistentes.

2. Si se presentan estados infecciosos concomitantes, tratar éstos primero antes de decidirse a intervenir. Se prescribirá reposo, anibióticos, Vitamina C y B, proteínas e instilaciones locales de sulfas en el endocervix, más bien que practicar técnicas intempestivas de raspađo, termocauterización o electrocoagulación. La cistoscopía para cerciorarse del estado de salud vesical se practicará siempre. Las investigaciones de flora microbiana vagino-uretral y las reacciones serológicas serán de rigor.

\section{B. Cuidados durante la operación.}

1. Tratar vejiga y ureteres con la misma suavidad y delicadeza con que se tratan oviductos y ovarios en operaciones conservadoras.

2. Incindir peritoneo de reflexión vesical lo más alto posible a expensas del de istma uterino, para tener después suficiente peritoneo sobrante que revista pared postero-inferior vesical y cara anterior de recto.

3. Evitar planos falsos de despegamiento vesical a expensas de sus tejidos y que se presentan cuando se usan gasa o torundas en lugar de tijeras curvas de punta roma durante la disección. Esta se hará en dos tiempos: primeramente superficial hasta encontrar vagina, secundariamente latero-vaginal y profunda, a expensas de tejidos no vesicales. 
4. Una vez extirpados órganos y tejidos enfermos se inspeccionan la situación de ureteres que casi siempre quedan pendientes y la extensión inferior de superficie vesical despegada que llega hasta el nivel del cuello vesical.

5. Introducir gasa yodoformada en vagina, dejando únicamente la punta insinuada fuera de sus bordes. Si se deja abundante gasa en la cavidad se pega a los ureteres irritándolos y podría adherirse a los mismos. Unir bordes laterales de vagina a muñones de utero-sacro respectivos.

6. Reconstruír el apoyo o firmeza de pared postero-inferior vesical para que reduzca la extensión de su lesión y su capacidad funcional, por medio de tres líneas de puntadas músculo-musculosas (catgut atraumático 0-00), de arriba abajo, de modo que al anudarlas por separado, formen una zona gruesa de pared vesical que cumpla el propósito mencionado. Si no es posible practicar estas puntadas lineales se construirán dos o tres jaretas concéntricas, siempre músculo-musculosas, por encima de la entrada de los ureteres, en el fondo de la pared vesical y que al cerrarlas principiando por la del centro, llenarán el mismo cometido. Se observará asimismo, que después de este tiempo los ureteres presentan una disminución de sinuosidades.

7. Llevar el peritoneo del borde superior vesical al límite inferior o base de vejiga peritonizando hasta allí, y de modo que quede un sobrante o pequeño delantal para revestir la superficie cruenta de cara anterior de recto en un tiempo ulterior. No se fijará este peritoneo a bordes vaginales por la marcada retracción consecutiva de esta última.

8. Reconstruír el lecho de los ureteres uniendo los bordes peritoneales pélvicos anteriores y posteriores en ambos lados y que se habian formado durante las incisiones del peritoneo parietal, si la búsqueda de los ureteres se hizo a nivel de la hipogástrica.

9. Peritonizar con el delantal peritoneal sobrante y de abajo arriba la superficie cruenta del recto.

Terminados estos tiempos se observará que la vejiga urinaria queda levantada y con mayor apoyo en su pared postero-inferior; pared anterior rectal peritonizada y entre estos dos órganos, un fondo de saco vesico-rectal que permite que las vísceras intestinales descansen en ese pequeño fondo ejerciendo presión posterior de soporte vesical. Se recordará que en la peritoni- 
zación común en que se une directamente peritoneo vesical a peritoneo pélvico y rectal, las asas intestinales descansan directamente sobre cara superior de vejiga urinaria, contribuyendo aún más, al descenso ya citado de la vejiga. Por otra parte, los ureteres quedan protegidos y el gran vacío del bajo fondo de la cavidad pelviana ha quedado reconstruído.

\section{Cuidados post-operatorios.}

1. Dejar sonda permanente en vejiga urinaria durante cuatro a ocho días a fin de mantenerla en reposo.

2. Administrar antibióticos. Una vez quitada la sonda, estimular la musculatura vesical con prostigmina, cloruro de betanicol, etc. Las instilaciones de $30 \mathrm{cc}$. de mercurio cromo al $0.5 \%$ estimulan asimismo el acto de la micción.

3. Deambulación precoz. El decúbito dorsal favorece la formación del fondo de saco vesical.

4. Si la orina residual permanece a más de 50 cc. y se presentan signos o síntomas de cistitis con incontinencia ortostática, solicitar la cooperación de un urólogo.

5. No dar de alta a la paciente hasta que haya micciones voIuntarias, orina residual normal y falta de manifestaciones infecciosas urinarias.

Los pocos casos que se han operado en el Pabellón 14 de Ginecología del Hospital General tomando en cuenta estas medidas, no constituyen, en verdad, una casuística, pero en todos ellos se ha tenido éxito habiéndose evitado los trastornos vesicales consecutivos a la operación radical de Wertheim dando fundadas esperanzas. En dichos pacientes, se ha quitado la sonda vesical permanente de los 4 a los 8 días, sondeándoseles después cada 24 horas siendo su orina residual entre $20 \mathrm{cc}$. y $80 \mathrm{cc}$., bajando esta última cantidad a $20 \mathrm{cc}$. en los pocos días. Los exámenes cistoscópicos post-operatorios no han presentado signos patológicos de importancia, aparte de algunos fenómenos congestivos banales y las pacientes han quedado aptas para ser dadas de alta, de los 12 a los 15 días de operadas, si no hubieran tenido que recibir terapia complementaria al tratamiento de sus neoplasias. 


\section{RESUMEN Y CONCLUSIONES}

I. Son discutibles las causas de la frecuente atonía e incontinencia vesical post-Wertheim.

II. Se considera como importante, desde el punto de vista fisopatológico, sobre todo, a la denervación para-simpática parcial de la vejiga que la operación ocasiona.

III. Se enfatizan, como causas contribuyentes, de gran trascendencia para la producción del Síndrome, a factores de orden mecánico, originados por la extirpación de gran parte de sostén de la vejiga. (Ligamentos pubo-vesico-uterinos, los cardinales, cervix, tabique vesico-vaginal, etc.).

IV. Se propone como tiempo adicional complementario de la operación de Wertheim, medidas tendientes a corregir estos trastornos de estática vesical.

V. Tales medidas incluyen:

1. Plegaduras o acortamiento de la superficie vesical cruenta y por lo tanto disminución de la zona sin sostén de dicho órgano, con la consiguiente reducción parcial de su capacidad.

2. Peritonización total de esta superficie vesical gracias a un delantal amplio de peritoneo vesico uterino, tomado a expensas de su porción uterina.

3. Finalmente, peritonización de la parte cruenta del recto, con la porción del delantal peritoneal sobrante, a manera de formar un verdadero fondo de saco de Douglas, semejante al masculino, que al permitir alojar en él las asas intestinales, proporciona cierta presión posterior de soporte vesical.

\section{BIBLIOGRAFIA}

BEST and TALOR. Physiological Basis of Medical Practice, pág. 689-691, third Edition, 1943.

CALATRONI-RUIz. Terapéutica Gineçlógica, pág. 757. 1951.

CROSSEN Y CROSSEN. Enfermedades de la Mujer, Tomo II, pág. 809. 1949.

GREENHILL, J. P. Radical Panhisterectomy with Pelvic Node Dissection. En "Surgical Ginecology", pág. 268. 1952.

KIRSCNER, M. Tratado de Técnica Operatoria General y Especial. Vol. VI, pág. 272. 1949.

LEARMONTH. Citado por C. F. V. Smout. (Anatomía de la Pelvis Femenina), pág. 205. 1945. 
LONGORIA, J. Incontinencia Ortostática de Orina, Rev. Gin. y Obst. de México, Vol. VI, No 3. Junio 1951.

MULLER, L. R. Sistema Nervioso Vegetativo, pág. 676. Tercera Edición. 1937 .

MARTIUS, H. Operaciones Ginecológicas, pág. 69. 1951.

MARION, G. Un Procedimiento para curar la Incontinencia Ortostática de Orina en la Mujer. Rev. de Urol. Org. Ofic. Soc. Mex. de Urol., Vol. VIII, № 1. Enero Febrero, 1950.

NOVAK, E. Texto de Ginecología, pág. 28. 1952.

PESQUEIRA, M. E. Uretro-Trigonitis en la Mujer. Rev. de Urol. Org. Ofic. Soc. Mex. de Urol., Vol. IX., No 3-131. May. y Jun. 1951.

QUIROZ GUTIERREZ, F. Anatomía Humana, Tomo III, pág. 217. 1945.

SMOUTH, C. F. V. Anatomía de la Pelvis Femenina, pág. 202. 1945.

STOECKEL, W. Tratado de Ginecología, pág. 43. 1949.

TE LINDE, R. W. Aspectos Urológicos de la Ginecología, Rev. Cubana de Obst. y Ginec. Vol. XIII No 1. Enero-Feb. 1951.

TE LINDE, R. W. Ginecología Operativa, pág. 388. 1948.

WHARTON. Ginecolgía incluyendo Urología Femenina, pág. 792. 1950.

WIGGER, C. J. Fisiología Normal y Patológica, pág. 789. 1949.

ZENTENO, G. Cinecología, pág. 345. 1947.

ZENTENO, G. Consideraciones Clínicas sobre los Estados previos al Cáncer Cervico-uterino, aplicadas a la Profilaxis y al Tratamiento Oportuno. Cirugía y Cirujanos. Tomo XIII, № 5, pág. 212. Mayo, 1945. 'qomo XIII. No 6. Pág. 261. Junio 1945.

ZUCKERMANN, C. Veintiún hechos importantes del cáncer in situ del cuello uterino. Rev. Mex. de Cirugía y Cáncer. Año XX, № 3. Marzo, 1952.

ZUCKermanN, C., URRUTIA, M. y GRAHAM, J. C. Estado Actual del Conocimiento del Cáncer in situ del cuello de la Matriz. 1952.

ZUCKERMANN, C. Cómo efectuamos la Operación de Wertheim. Rev. Mex. Ginec. y Cáncer, pág. 9. Año XIX, No 4. Abril, 1951. 